\title{
Exfoliation of graphene via wet chemical routes
}

\author{
Khaled Parvez ${ }^{a}$, Sheng Yang ${ }^{\mathrm{a}}$, Xinliang Feng ${ }^{\mathrm{b}, *}$, Klaus Müllen ${ }^{\mathrm{a}, *}$ \\ a Max Planck Institute for Polymer Research, Ackermannweg, 55128 Mainz, Germany \\ ${ }^{\mathrm{b}}$ Center for Advancing Electronics Dresden (cfaed) E Department of Chemistry and Food Chemistry, Technische Universität Dresden, 01062 Dresden, \\ Germany
}

\section{A R T I C L E I N F O}

\section{Article history:}

Received 14 January 2015

Received in revised form 6 July 2015

Accepted 7 July 2015

Available online 14 August 2015

\section{Keywords:}

Graphene

Exfoliation

Wet-chemistry

\begin{abstract}
A B S T R A C T
Graphene is a two-dimensional material that has fascinating electrical and optical properties, and this material has provided chemists with great possibilities and challenges. Interests in graphene's exceptional physical and chemical properties and in its potential for applications have generated thousands of publications and have accelerated the pace of graphene research. Although considerable scientific progress has been achieved, the key to commercializing graphene lies in the cost-effective and scalable production of this material. Graphene can be produced using a variety of wet chemical methods, such as chemical oxidation followed by exfoliation, liquid-phase and electrochemical assisted exfoliation etc. from inexpensive and abundant sources such as graphite. This review article summarizes the recent progress toward the preparation of graphene through wet chemical routes and discusses their remaining challenges. In particular, the quality and yield of graphene sheets produced using these exfoliation protocols will be emphasized.
\end{abstract}

(C) 2015 Elsevier B.V. All rights reserved.

\section{Introduction}

Graphene is an atomically thin layer of $\mathrm{sp}^{2}$-hybridized carbon atoms arranged in a honeycomb lattice, and it exhibits remarkable electronic, thermal and mechanical properties [1-3]. Over the past decade, graphene has emerged as an exciting new material with the potential to impact many areas of science and technology. In fact, the research in this field started in the 1840s, when the intercalation compounds of graphite were first reported [4]. However, the observation of graphitic carbon monolayers by scientists dates back to the 1960 s, when $\mathrm{SiC}$ was heated to $2150^{\circ} \mathrm{C}$ [5]. The exfoliation of graphite into individual graphene sheets remained out of reach until 2004, when the isolation of graphene using a simple scotch tape method was reported [6,7]. The isolated graphene was found to exhibit a high charge carrier mobility $\left(2 \times 10^{5} \mathrm{~cm}^{2} / \mathrm{V} \mathrm{s}\right)[8]$, high thermal conductivity ( $5000 \mathrm{~W} / \mathrm{mK})$ [9], exceptional Young's modulus ( $\sim 1.0 \mathrm{TPa})[10]$ and large theoretical specific surface area $\left(2630 \mathrm{~m}^{2} / \mathrm{g}\right)$ [11]. Moreover, a single graphene layer absorbs only $2.3 \%$ of incident light and therefore has a transparency of $97.7 \%$ [12]. The combination of high electrical conductivity, chemical and thermal stability, and excellent stretchability provides

\footnotetext{
* Corresponding authors.

E-mail addresses: xinliang.feng@tu-dresden.de (X. Feng), muellen@mpip-mainz.mpg.de (K. Müllen).
}

considerable advantages for the use of graphene in electronic devices such as solar cells [13], organic light-emitting diodes [14], field-effect transistors $[15,16]$, photodetectors $[17,18]$, and touch screens [19]. Moreover, graphene has also been demonstrated to be a promising electrode material for fuel cells [20,21], supercapacitors [22-24] and lithium-ion batteries [25] because of its excellent electrical conductivity and high surface area.

Pristine graphene can be obtained through micromechanical cleavage [6]. Unfortunately, this method only yields an extremely small amount of sample, which is only useful for fundamental research. Chemical vapor deposition (CVD) [26] can produce graphene over a large area and with a relatively small number of defects, making this protocol promising for electronic device applications that utilize the high transparency and high electrical conductivity of graphene. Nevertheless, this metallic surface-mediated method cannot be readily scaled up for the bulk production of graphene for applications. Considering the natural abundance of graphite flakes, the wet chemical approaches for graphite exfoliation may be feasible for the large-scale production of graphene. Moreover, the wet chemical methods are also versatile in terms of covalent and non-covalent functionalization, which can generate a variety of graphene and graphene-based materials.

This review article will discuss the bulk production of graphene via wet chemical exfoliation methods which typically involve the processes of chemical reaction, electrochemical reaction or solvent/surfactant assisted functionalization and exfoliation in the 


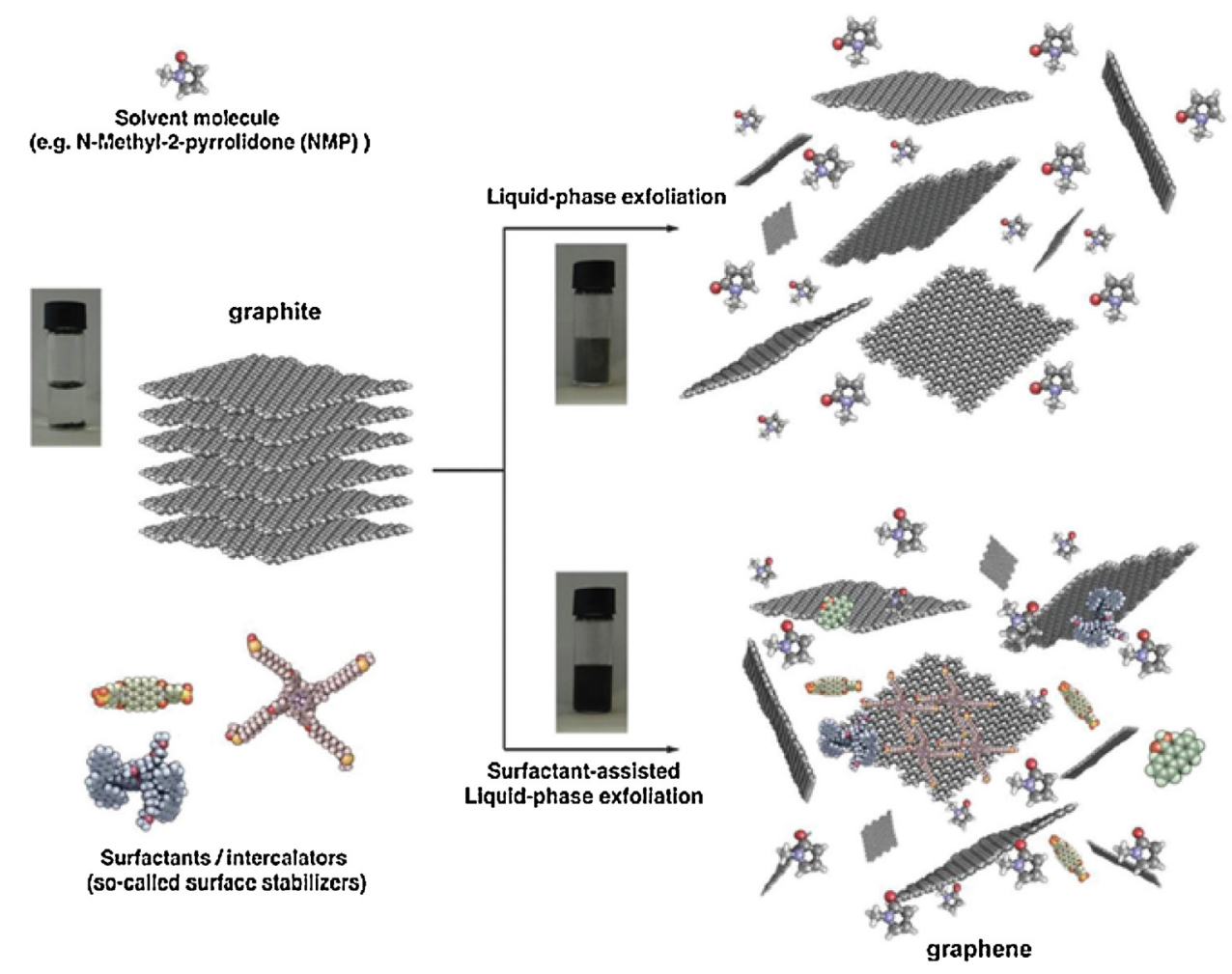

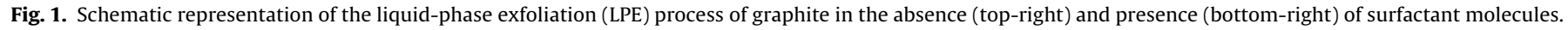
Reproduced from Ref. [43] with permission from the Royal Chemical Society.

solutions, with the major focus on the exfoliation protocols, yields and quality of graphene sheets. Some of the recent developments on the well-known graphite exfoliation processes, namely, liquidphase exfoliation, reduction of graphite oxide and electrochemical exfoliation techniques, as well as their challenges will be discussed in detail. The dry chemical exfoliation methods from graphite, like ball-milling assisted by chemical functionalization [27] will not be discussed due to the low efficiency and/or scalability compared to the wet chemical exfoliation methods.

\section{Liquid-phase exfoliation (LPE)}

Liquid-phase exfoliation (LPE) typically involves a dispersion of graphite in a solvent mediated by an exfoliation process to extract individual layers (Fig. 1) [28-30]. The successful exfoliation of graphene layers requires overcoming the van der Waals forces between the adjacent layers. One of the most effective and straightforward methods for reducing the strength of the van der Waals forces is to immerse graphite into a liquid medium, where the potential energy between adjacent layers receives contributions from dispersive London interactions, which in the presence of a solvent are significantly lower than that in vacuum. The surface energy of graphene has been estimated to be $46.7 \mathrm{mN} / \mathrm{m}$ [31]. Therefore, solvents with a surface tension of $\sim 40 \mathrm{mN} / \mathrm{m}$, such as $\mathrm{N}$-methylpyrrolidone (NMP, $40 \mathrm{mN} / \mathrm{m}$ ), N,N'-dimethylformamide (DMF, $37.1 \mathrm{mN} / \mathrm{m}$ ), $\gamma$-butyrolactone (GBL, $35.4 \mathrm{mN} / \mathrm{m}$ ), and orthodichlorobenzene (o-DCB, $37 \mathrm{mN} / \mathrm{m}$ ), are the best media for the exfoliation of graphite because they minimize the interfacial tension between the solvent and the graphene layer. The first successful LPE of graphite was achieved in NMP [28]. The obtained graphene sheets are considered to be pristine graphene because no chemical functionalization is involved. After centrifuging to remove the unexfoliated bulk material, the remaining samples consist of $28 \%$ monolayer graphene. A thin film fabricated from LPE graphene presents a conductivity value of $\sim 6500 \mathrm{~S} / \mathrm{m}$.
Unfortunately, the overall yield of monolayer graphene is very low, approximately $1 \mathrm{wt} \%$ with a concentration of $0.01 \mathrm{mg} / \mathrm{mL}$. Further optimization of the solvents led to some improvements in the dispersibility of graphene. For instance, concentrations as high as $0.03 \mathrm{mg} / \mathrm{mL}, 0.1 \mathrm{mg} / \mathrm{mL}$ and $0.5 \mathrm{mg} / \mathrm{mL}$ were achieved using o-DCB [32] and perfluorinated aromatic solvents such as pentafluorobenzonitrile [33] and benzylamine [34], respectively. However, due to the long ultrasonication process, the lateral dimension of LPE graphene is relatively small $(<3 \mu \mathrm{m})$. Nevertheless, despite the low yield and small flake size, LPE graphene is of high quality, and the field-effect mobility measured for an ink-jetprinted graphene film was reported to be as high as $95 \mathrm{~cm}^{2} / \mathrm{V} \mathrm{s}$ [35].

Several attempts have been made to increase the concentration and the yield of LPE graphene by functionalization with small organic molecules during the exfoliation process. For example, large graphene flakes can be produced by the addition of $\mathrm{N}-2$ mercapto-propionyl glycine (tiopronin) during the exfoliation of graphite in DMF [36]. It is hypothesized that ultrasonication in organic solvents generates free radicals, such as peroxyl radicals. These radical species are strong enough to oxidize graphene sheets, initially at the edges and inner defects, thereby cutting the graphene into small pieces. The addition of tiopronin during the LPE process can inhibit reactions promoted by oxygen, peroxides and radicals, thereby preventing the graphene sheets from breaking into small pieces to some extent. As-prepared LPE graphene yielded a concentration of $0.027 \mathrm{mg} / \mathrm{mL}$, with the majority of the graphene sheets in the size range of $2-5 \mu \mathrm{m}$. In another attempt, LPE graphene in chloroform was covalently functionalized with 4-tertbutylphenyldiazonium tetrafluoroborate (BPD) [37]. As a result, concentrations of $1.2 \mu \mathrm{g} / \mathrm{mL}$ for medium BPD-functionalized and $27 \mu \mathrm{g} / \mathrm{mL}$ for highly BPD-functionalized graphene were obtained. The intact graphene layers could be fully restored by thermal treatment of the functionalized graphene material. Recently, Samori and co-workers reported that simple alkane molecules, such as 
1-phenyloctane and arachidic acid, can promote the LPE process. Both of these molecules can undergo self-assembly on the graphite surface and thereby increase the graphene exfoliation yields [38]. The exfoliation of graphene in NMP in the presence of arachidic acid resulted in a concentration of $0.13 \mathrm{mg} / \mathrm{mL}$, with $23 \%$ monolayer graphene. On the other hand, LPE in 1-phenyloctane resulted in a higher yield (28\%) of graphene but a slightly lower concentration (i.e., $0.10 \mathrm{mg} / \mathrm{mL}$ ). Further improvements of thin layer graphene in NMP, o-DCB, DMF and 1,2,4-trichlorobenzene (TCB) were achieved by the same group in the presence of fatty acids with different chain lengths, such as hexanoic acid (C6), lauric acid (C12), stearic acid (C18), lignoceric acid (C24) and melissic acid (C30) [39]. The concentration of the graphene dispersion was found to be proportional to the length of the employed fatty acids. For example, LPE with C30 resulted in a $200 \%$ increase in the exfoliation yield, with nearly $50 \%$ monolayer graphene, compared to exfoliation in pure NMP.

Despite the significant progress achieved in the exfoliation of graphite, the majority of organic solvents with a surface tension of $\sim 40 \mathrm{mN} / \mathrm{m}$ have high boiling points and toxicities. Therefore, a stable dispersion of graphene in low-boiling-point solvents, such as ethanol, acetonitrile and methanol, is highly desirable. Several attempts to produce graphene by LPE in low-boiling-point solvents have been reported. One approach is the solvothermal-assisted exfoliation of expanded graphite in a polar organic solvent, such as acetonitrile [40]. It has been demonstrated that the dipole-induced interactions between graphene and acetonitrile facilitated the exfoliation of graphene, which resulted in a yield of $\sim 10 \mathrm{wt} \%$ graphene. More recently, a dispersion of graphene in ethanol was reported by solvent exchange from NMP [41]. The exfoliated graphene in NMP was first filtered through a polytetrafluoroethylene (PTFE) membrane, followed by re-dispersion of the filter cake into ethanol. After several centrifuging and washing steps, a stable dispersion of graphene in ethanol with a concentration of $0.04 \mathrm{mg} / \mathrm{mL}$ was achieved. Nevertheless, this graphene dispersion led to $20 \%$ sedimentation after one week. Recently, we reported the LPE of graphene in polar solvents mediated by a novel water-soluble surfactant consisting of hexa-peri-hexabenzocoronene (HBC) as a hydrophobic aromatic core and hydrophilic carboxy substituents [42]. Resulting from the strong $\pi$ interactions between the large aromatic core and the graphene surface, a graphene dispersion with a concentration of $1.1 \mathrm{mg} / \mathrm{mL}$ in methanol containing 2-6 multilayer nanosheets was obtained.

Water is a natural solvent choice because of its non-toxicity, which can provide possibilities for manipulation, in particular, thin film fabrication. However, the exfoliation of graphene in water is highly challenging because of its high surface tension $(\sim 72 \mathrm{mN} / \mathrm{m})$ and incompatibility with the hydrophobic nature of graphene sheets. This can be partially overcome through the use of surfactants, which allow exfoliated sheets to remain in suspension. For example, anionic surfactants such as 4-dodecylbenzenesulfonic acid (SDBS) [29], sodium cholate (SC) [44] and sodium deoxycholate (SDC) $[45,46]$ have been reported to successfully exfoliate graphite with concentrations up to $0.3 \mathrm{mg} / \mathrm{mL}$ in water. Moreover, in a rigorous investigation on surfactant-assisted graphite exfoliation in water, a variety of ionic and nonionic surfactants were explored (Fig. 2) [47,48]. In general, nonionic surfactants, which have a hydrophobic tail and a long hydrophilic part, outperformed their ionic counterparts because of the ability to suspend graphene in water. The steric repulsion between the hydrophilic moieties in water is essential for stabilizing the graphene dispersion. For example, a dispersion of $\sim 1 \mathrm{mg} / \mathrm{mL}$ of graphene was achieved by adding triblock copolymer Pluronic ${ }^{\circledR}$ P-123 after two hours of sonication. Furthermore, increasing the sonication time to five hours yielded a concentration of $1.5 \mathrm{mg} / \mathrm{mL}$. Atomic force microscopy (AFM) analysis revealed that the graphene sheets had lateral sizes in the range of hundreds of nanometers with less

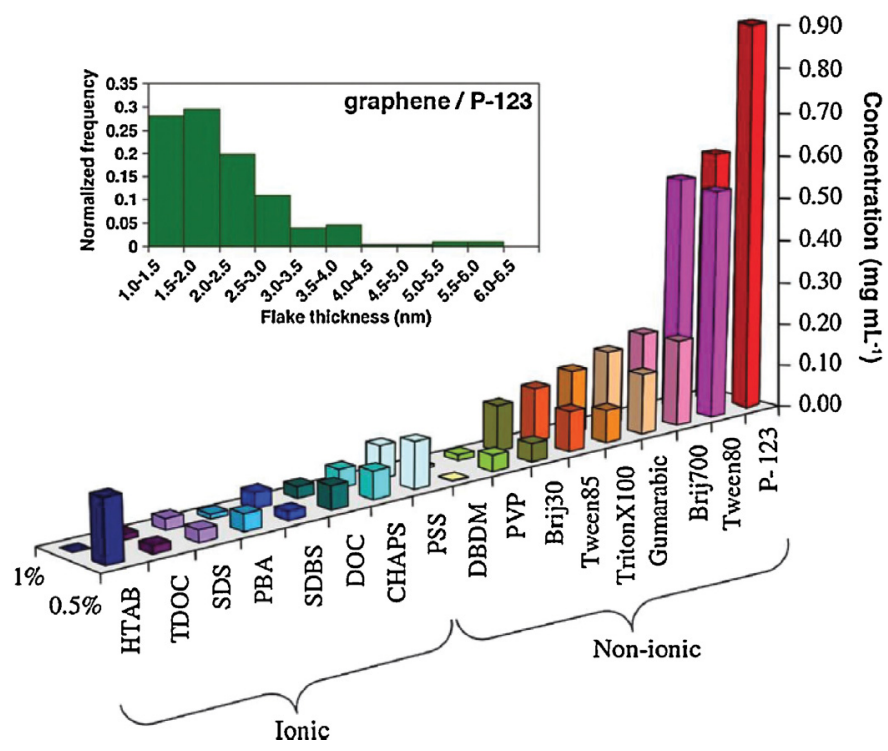

Fig. 2. Concentration of graphene in aqueous dispersions achieved by the use of different surfactants, as estimated from UV-Vis absorption measurements. Two surfactant concentrations are shown: $0.5 \%$ and $1.0 \% \mathrm{wt} / \mathrm{vol}$. Inset figure-histogram showing the distribution of apparent flake thickness measured by AFM of 200 objects from dispersions stabilized by the non-ionic triblock copolymer P-123.

Reproduced from Ref. [47] with permission from Elsevier.

than 5 layers (10-15\% monolayer graphene). Moreover, the Raman spectra revealed an intensity ratio of $D$ to $G$ band (also known as $I_{\mathrm{D}} / I_{\mathrm{G}}$ ratio and is used to estimate the defect density of graphene sheets) was only 0.10 , which is primarily attributed to the edges of the small graphene flakes. Nevertheless, depending on the final application of graphene, the presence of surfactant may be problematic, e.g., compromising or decreasing the conductivity of graphene. Moreover, the cost of the surfactant increases the issues of added expense if the process is to be scaled up.

In addition to LPE in organic and water-based solvents, ionic liquids have emerged as promising solvents to aid in the sonicationbased exfoliation of graphite. Ionic liquids are salts that exist in the liquid state below $100^{\circ} \mathrm{C}$ and that often have surface energies close to that of graphene (i.e., $40 \mathrm{mN} / \mathrm{m}$ ). One of the first ionic liquids used for the exfoliation of graphite was 1-butyl-3-methylimidazolium bis(trifluoromethanesulfonyl)imide, which led to a $0.95 \mathrm{mg} / \mathrm{mL}$ stable dispersion of graphene nanosheets with $1 \mathrm{~h}$ of sonication [49]. This work demonstrated that the majority of the graphene sheets were less than 5 layers. Recently, the prolonged sonication ( $24 \mathrm{~h}$ ) of graphite flakes in 1-hexyl-3-methylimidazolium hexafluorophosphate (HMIM) yielded a stable graphene dispersion with a concentration as high as $5.33 \mathrm{mg} / \mathrm{mL}$ and an average thickness of $2 \mathrm{~nm}$ for the graphene flakes. Unfortunately, the yield of exfoliated graphene was only approximately $1-2 \mathrm{wt} \%$ [50].

Although attempts have been made to further promote the exfoliation process by using expanded graphite or graphite intercalation compounds [51-53], the bottleneck of the LPE process lies in the limited dispersibility of pristine graphene. Nevertheless, LPE is a mild, versatile and potentially up-scalable approach for obtaining high-quality graphene using equipment available in all chemistry labs.

\section{Graphene from graphite oxide}

One of the low-cost methods for the large-scale production of graphene is the reduction of graphite oxide or graphene oxide to graphene. This method is currently the most popular wet chemical method for producing graphene materials because of its potential 

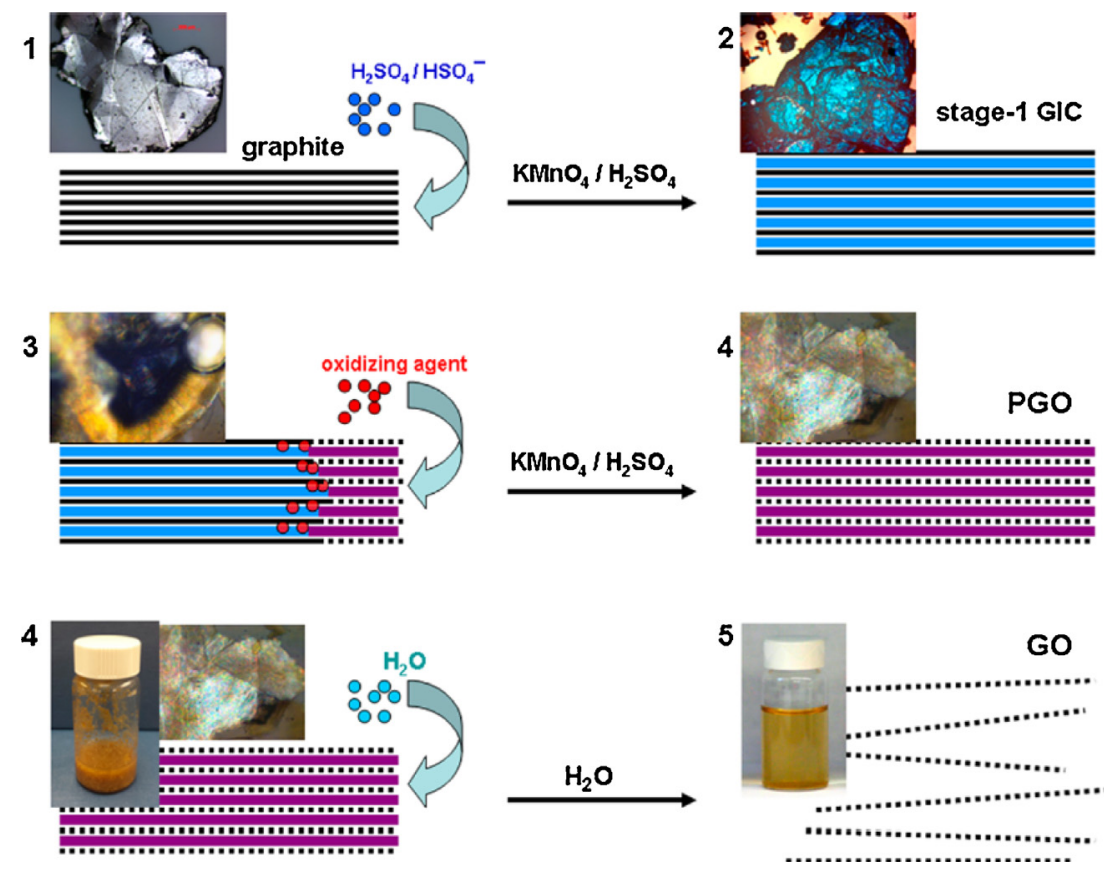

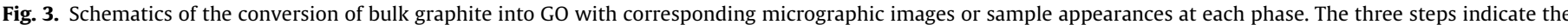

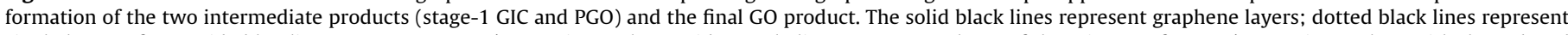

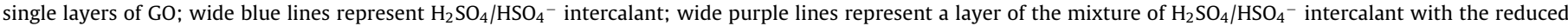
form of oxidizing agent. (For interpretation of the references to color in this figure legend, the reader is referred to the web version of this article.)

Reproduced from Ref. [59] with permission from the American Chemical Society.

scalability, high yield and excellent dispersibility in various solvents, which facilitates processability toward many applications [54-56]. Both the chemical structure and properties of graphene oxide (GO) have been extensively covered in numerous reviews and are therefore not described in detail here. In this review article, we will only briefly describe some recent advancement in the GO preparation and reduction methods that lead to highly reduced graphene. The comparison of various reduced GO in terms of quality, electronic properties etc. will be discussed in the context.

The Hummers method is the most frequently used protocol for preparing graphite oxide and its single layers (i.e., graphene oxide), which are obtained after delamination in a suitable solvent by sonication [57]. This method consists of treating graphite with a mixture of sodium nitrate, potassium permanganate and sulfuric acid. Over the years, efforts have been made to improve the Hummers method by eliminating the use of sodium nitrate, thus preventing the production of toxic nitrous gas [58]. The addition of phosphoric acid led to a higher yield of GO with a higher degree of oxidation. As shown in Fig. 3, the mechanism for the formation of GO was recently defined in three distinct, independent steps [59]. The active oxidizing species is dimanganese heptoxide $\left(\mathrm{Mn}_{2} \mathrm{O}_{7}\right)$, which is formed when potassium permanganate reacts with sulfuric acid [60]. However, $\mathrm{Mn}_{2} \mathrm{O}_{7}$ is known to detonate when heated to temperatures above $55^{\circ} \mathrm{C}$ or when in contact with organic compounds [61]. Therefore, controlling the temperature in such a high-risk reaction is of crucial importance, particularly at the industrial scale. Recently, the preparation of GO (named 'GO-n') with an almost intact $\sigma$ framework of carbon atoms was achieved by controlling the reaction temperature at $5-10^{\circ} \mathrm{C}$ during the oxidation step, thereby preventing a large extent of the overoxidation of graphene layers [62]. Under such conditions, the formation of $\mathrm{CO}_{2}$ during the oxidation step can be minimized. Moreover, cold water was continuously added to the mixture over a period of one day to avoid heating the concentrated sulfuric acid, which the authors claimed to be an essential step to preserve the carbon framework in GO. However, the yield of GO- $n$ was lower ( $\sim 56 \%)$ compared to that of conventionally prepared GO (i.e., GO-c). The flake size of GO- $n$ was determined to be $2-10 \mu \mathrm{m}$. Although both XPS and FTIR analyses did not reveal any significant differences between GO- $n$ and GO- $c$, the GO- $n$ reduced by the vapor of hydriodic acid and trifluoroacetic acid presented an $I_{\mathrm{D}} / I_{\mathrm{G}}$ ratio of $<1$ and a charge carrier mobility of $250 \mathrm{~cm}^{2} / \mathrm{V} \mathrm{s}$ for holes and $200 \mathrm{~cm}^{2} / \mathrm{Vs}$ for electrons. In contrast, conventionally reduced $\mathrm{GO}$ typically exhibits an $I_{\mathrm{D}} / I_{\mathrm{G}}$ ratio of $>1$ and carrier mobility in the range of $0.01-12 \mathrm{~cm}^{2} / \mathrm{V} \mathrm{s}$ [63-67].

Although GO can form a homogeneous colloidal suspension, there are other concerns associated with GO, such as its chemical inhomogeneity, batch-to-batch reproducibility and the inevitable generation of irreversible defects on graphene sheets during oxidation. Moreover, GO is electrically insulating due to the disruption of the 'graphitic' networks. To restore the electronic property of graphene, chemical or thermal reduction of GO is required to partially remove the oxygen functional groups. The reduction of GO has been widely explored over the past decade [85]. In general, the chemical reduction of GO sheets has been performed with reducing agents such as hydrazine $\left(\mathrm{N}_{2} \mathrm{H}_{4}\right)$ [68], sodium borohydride $\left(\mathrm{NaBH}_{4}\right)$ [86], dimethyl hydrazine [87], and hydriodic acid (HI) [71,72]. Very recently, a highly efficient chemical reduction of GO was achieved in a sodium-ammonia ( $\left.\mathrm{Na}-\mathrm{NH}_{3}\right)$ system [74]. The addition of pieces of $\mathrm{Na}$ metal to a GO dispersion in liquid $\mathrm{NH}_{3}$ and keeping the mixture in a dry ice-acetone bath for $30 \mathrm{~min}$ resulted in highly reduced GO. The obtained material exhibited a high C/O ratio of 16.61 and a small amount of nitrogen doping (0.86 at\%). Notably, this reduced GO exhibited a sheet resistance of only $350 \Omega$ /sq and a hole mobility as high as $123 \mathrm{~cm}^{2} / \mathrm{Vs}$.

In general, the quality of reduced GO strongly depends on the types of reducing agents and/or other parameters such as temperature. Table 1 compares some of the most frequently used reduction methods for GO and properties of the as-reduced GO, such as their $\mathrm{C} / \mathrm{O}$ ratio, charge carrier mobility and electrical conductivity. Note that, despite the various reduction methods used to obtain reduced $\mathrm{GO}$, the defects in GO caused by the severe oxidation process during their preparation cannot be fully removed. 
Table 1

List of reduction methods for graphene oxide toward reduced graphene oxide.

\begin{tabular}{|c|c|c|c|c|c|}
\hline \multirow[t]{2}{*}{ GO reduction methods } & \multirow[t]{2}{*}{$\begin{array}{l}\text { Reduction } \\
\text { processes }\end{array}$} & \multirow[t]{2}{*}{$\mathrm{C} / \mathrm{O}$ ratio } & \multicolumn{2}{|l|}{$\begin{array}{l}\text { Electronic } \\
\text { properties }\end{array}$} & \multirow[t]{2}{*}{ Ref. } \\
\hline & & & $\begin{array}{l}\text { Mobility } \\
\left(\mathrm{cm}^{2} / \mathrm{Vs}\right)\end{array}$ & $\begin{array}{l}\text { Conductivity } \\
(\mathrm{S} / \mathrm{m})\end{array}$ & \\
\hline \multirow{11}{*}{ Chemical reduction } & Hydrazine & $10.3^{b}$ & - & 2420 & {$[68]$} \\
\hline & Phenylhydrazine & $9.51^{\mathrm{b}}$ & - & 4700 & [69] \\
\hline & $\mathrm{NH}_{3}-\mathrm{BH}_{3}$ & $9.8^{\mathrm{a}}$ & - & 20,300 & [70] \\
\hline & $55 \% \mathrm{HI}$ acid & $12.0^{\mathrm{a}}$ & - & 29,800 & [71] \\
\hline & $\mathrm{HI}-\mathrm{AcOH}$ & $11.5^{\mathrm{b}}$ & - & 30,400 & {$[72]$} \\
\hline & Ethylenediamine & $7.8^{\mathrm{a}}$ & - & 220 & [73] \\
\hline & $\mathrm{Na}-\mathrm{NH}_{3}$ & $16.61^{\mathrm{a}}$ & 123 (hole) & & [74] \\
\hline & $\begin{array}{l}\text { Nascent hydrogen } \\
(\mathrm{Al} / \mathrm{HCl})\end{array}$ & $21.11^{\mathrm{b}}$ & - & 12,530 & {$[75]$} \\
\hline & $\begin{array}{l}\mathrm{HI}+\text { trifluoroacetic } \\
\text { acid }\end{array}$ & $10.49^{\mathrm{a}}$ & $\begin{array}{l}250 \text { (hole) } \\
200 \text { (electron) }\end{array}$ & & {$[62]$} \\
\hline & $\mathrm{Zn} / \mathrm{HCl}$ & $33.5^{\mathrm{a}}$ & - & $1.5 \times 10^{4}$ & {$[76]$} \\
\hline & $\begin{array}{l}\text { Thiourea } \\
\text { dioxide/NaOH }\end{array}$ & $14.5^{\mathrm{a}}$ & - & & {$[77]$} \\
\hline \multirow{3}{*}{ Thermal reduction } & $700^{\circ} \mathrm{C}, \mathrm{H}_{2}, 30 \mathrm{~min}$ & $28.57^{\mathrm{a}}$ & - & $8.1 \times 10^{3}$ & [78] \\
\hline & $1000^{\circ} \mathrm{C}, \mathrm{H}_{2}, 1 \mathrm{~h}$ & - & $\begin{array}{l}5.4 \text { (hole) } \\
1.1 \text { (electron) }\end{array}$ & $7.6 \times 10^{4}$ & [79] \\
\hline & $\begin{array}{l}1000^{\circ} \mathrm{C}, \mathrm{C}_{2} \mathrm{H}_{2}, \\
30 \mathrm{~min}\end{array}$ & $50.2^{\mathrm{a}}$ & - & $1.43 \times 10^{5}$ & {$[80]$} \\
\hline \multirow[t]{2}{*}{ Plasma-assisted reduction } & $\begin{array}{l}\mathrm{CH}_{4} \text { plasma, } 700^{\circ} \mathrm{C} \text {, } \\
20 \mathrm{~s}\end{array}$ & $9.2^{\mathrm{a}}$ & - & $3.45 \times 10^{4}$ & {$[23]$} \\
\hline & $\begin{array}{l}\mathrm{Ar} / \mathrm{H}_{2} \text { plasma, } \\
150^{\circ} \mathrm{C}, 30 \mathrm{~min}\end{array}$ & $6.95^{\mathrm{a}}$ & - & & [81] \\
\hline Photocatalytic reduction & $\begin{array}{l}\text { Polyoxometalate } \\
\text { cluster } \\
\left(\mathrm{H}_{3} \mathrm{PW}_{12} \mathrm{O}_{40}\right)\end{array}$ & - & $\begin{array}{l}0.03 \text { (hole) } \\
0.01 \text { (electron) }\end{array}$ & 120 & [82] \\
\hline \multirow[t]{2}{*}{ Solvothermal reduction } & $\begin{array}{l}\mathrm{DMF}+0.6 \mathrm{M} \mathrm{H}_{2} \mathrm{SO}_{4} \text {, } \\
1 \mathrm{~h}\end{array}$ & $8.4^{\mathrm{a}}$ & - & 1223 & {$[83]$} \\
\hline & $\begin{array}{l}\mathrm{H}_{2} \mathrm{O}: \mathrm{NMP}(1: 1) \\
200^{\circ} \mathrm{C}, 24 \mathrm{~h}\end{array}$ & $5.15^{\mathrm{a}}$ & - & 374 & {$[84]$} \\
\hline
\end{tabular}

\footnotetext{
a X-ray photoelectron spectroscopy (XPS).
}

b Elemental analysis.

\section{Electrochemical exfoliation of graphite}

As early as the 1970s, electrochemical methods were conventionally used for the preparation of graphite intercalated compounds (GICs) [88]. However, it was not until recent years that this old topic intrigued chemists as straightforward routes for the synthesis of graphene. Generally, the electrochemical method utilizes a liquid conductive electrolyte and a direct current to drive structural expansion within graphitic precursors (e.g., rod, flake, or plate). When exposed to an electric field, a graphite electrode can be either positively or negatively intercalated, further exfoliated by the gases from solvent electrolysis or by post treatment. Unlike other routes (e.g., liquid-phase exfoliation, reduction of GO) discussed in the above sections, the electrochemical method offers a number of potential advantages, including (1) great ease of operation (executable at ambient temperature) and control over the synthesis process (functionalization and/or exfoliation can be tuned by varying the electrolysis parameters); (2) relatively fast synthesis rates and scalable mass production potential (gram-scale quantity in tens of minutes based on electrochemical cell engineering); and (3) being more environmentally benign (elimination of apparent pollution by recycling the use of electrolytes) [89]. Note that the electrolytes play a crucial role in the overall exfoliation process. Many research groups have made considerable progress toward investigating electrolytes for graphite exfoliation, and these efforts have greatly contributed to our knowledge of the exfoliation process. In this section, we will discuss the electrochemical exfoliation according to the categories of selected electrolytes, namely, aqueous and non-aqueous electrolytes.

\subsection{Non-aqueous electrolyte}

Non-aqueous solvents are ideal for electrochemical reactions because they provide wide electrochemical windows [90,91]. Notably, graphite generally serves as a cathodic electrode, and an electric field will promote the intercalation of cations (e.g., lithium ions and alkyl-ammonium ions) to expand the graphite interlayer distance. The application of a negative potential to the graphite electrode prevents excess oxidation, thereby preserving the pristine graphitic structure. Simulating the undesirable side effect between graphite electrodes and organic carbonates in lithium-ion batteries, Wang et al. [92] successfully isolated few-layer graphene through the electrochemical intercalation of lithium ions in a propylene carbonate electrolyte by applying a high negative potential $(-15 \mathrm{~V})$ followed by prolonged sonication in DMF. Consequently, over $70 \%$ of the obtained graphene sheets had a thickness of less than five layers. Unfortunately, more than $80 \%$ of the graphene sheets were less than $2 \mu \mathrm{m}$ due to the long sonication time. Later, further improvement was achieved by using a two-stage process, with an initial expansion of graphite in propylene carbonate containing lithium perchlorate $\left(\mathrm{LiClO}_{4}\right)$ followed by a second expansion in tetra-n-butylammonium electrolyte. A potential of $-5 \mathrm{~V}$ was applied for both stages (Fig. 4). Then, a mild ultrasonication ( $\mathrm{ca} .15 \mathrm{~min}$ ) was performed to obtain the graphene dispersion. In addition, a direct electrochemical functionalization with aryl diazonium salt was also performed on the expanded graphite to obtain functionalized graphene sheets [93]. The resulting graphene flakes exhibited a lateral size of tens of micrometers with a yield of $30-40 \%$ thin layer graphene. However, 


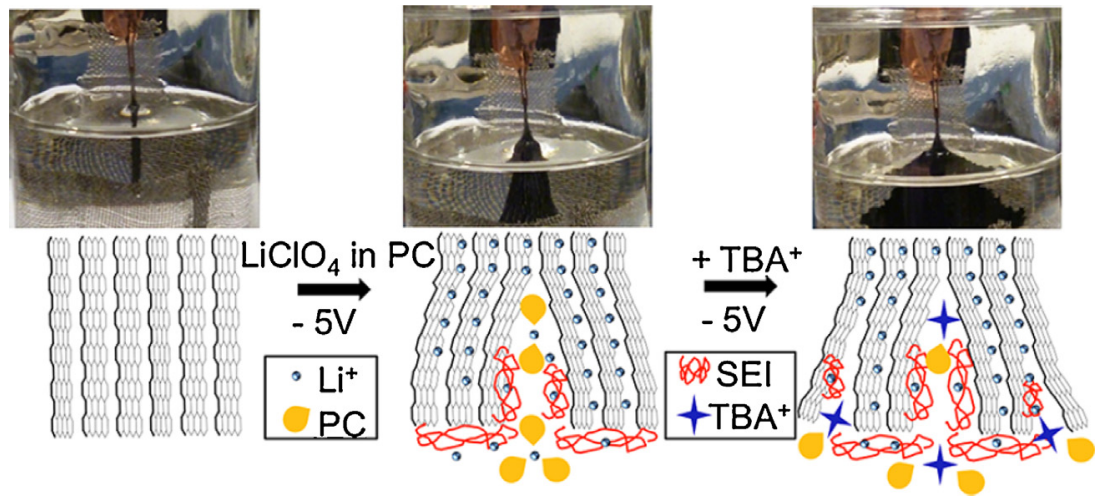

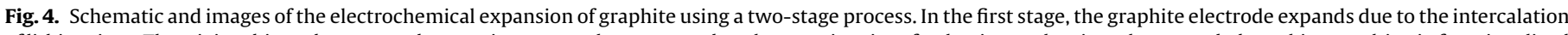

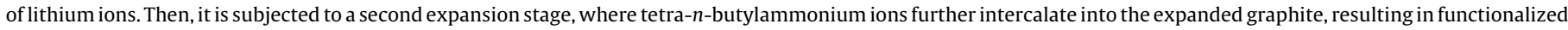
exfoliated graphene.

Reproduced from Ref. [93] with permission from the American Chemical Society.

the long intercalation and exfoliation times $(>10 \mathrm{~h})$ in both cases are not appealing for practical applications.

Recently, various types of other organic solvents (e.g., dimethyl sulfoxide (DMSO) [94], 1-methyl-2-pyrrolidone (NMP) [95] or acetonitrile [96]) were used to disperse inorganic salts (e.g., lithium salts, small alkylammonium molecules or perchlorate salts) as electrolytes for electrochemical exfoliation. However, the exfoliation methods are similar to the ones mentioned above, for example, graphite was used as the cathode and a long intercalation time $(\sim 10 \mathrm{~h})$ or post-treatment (microwave irradiation) was required to achieve efficient exfoliation. Moreover, multilayer graphene $(>5$ layers) appeared to be the dominant product, and the solvents used in these cases were either volatile or toxic. These disadvantages obstruct their practical applications (Table 2).

In the family of organic electrolytes, ionic liquids (ILs) are another important branch. However, a small amount of water is in fact required in this system because the interplay between the electrolysis of water and the intercalation of IL ions is crucial for the exfoliation. Previous studies have demonstrated that imidazoliumbased ionic liquids provide opportunities for exfoliation and for the in situ functionalization of graphene. Depending on the water content in the ILs, the exfoliated materials ranged from water-soluble oxidized graphene (ILs with over $10 \%$ water content) [90] to ILfunctionalized graphene (concentrated ILs, less than $10 \%$ water) [91]. Nevertheless, the adsorption, intercalation and possible side reactions of the IL moieties on a graphite electrode have a passive impact on both the exfoliation efficiency and graphene quality.

Table 2

Outline of the advantages and disadvantages of each electrolyte for graphite exfoliation.

\begin{tabular}{lll}
\hline & Advantages & Disadvantages \\
\hline $\begin{array}{l}\text { Aqueous electrolytes } \\
\left(\mathrm{M}_{2} \mathrm{SO}_{4}\left(\mathrm{M}=\mathrm{H}^{+}, \mathrm{Na}^{+},\right.\right.\end{array}$ & Low cost & Environmental \\
$\left.\mathrm{K}^{+}, \mathrm{NH}_{4}^{+}\right) ; \mathrm{HX}\left(\mathrm{X}=\mathrm{Cl}^{-}\right.$, & friendliness & Flake size homogeneity \\
$\left.\mathrm{Br}^{-}, \mathrm{NO}_{3}{ }^{-}, \mathrm{ClO}_{4}^{-}\right) ;$ & Rapid production & \\
$\mathrm{NaOH} / \mathrm{H}_{2} \mathrm{O}_{2}$, etc. $)$ & High yield & \\
& High processability & \\
Non-aqueous & Non-oxidation & High cost \\
electrolytes & Ease of & Environmental hazards \\
$\left(\mathrm{Li}{ }^{+}\right.$or & electrochemistry & Predominant multiple \\
alkyl-ammonium & & layers \\
cations (MeNH & & Low yield \\
EtNH & Low processability \\
Propylene Carbon- & & Time consuming \\
ate/DMSO/NMP; Room & & \\
temperature ionic & & \\
liquids, etc.) & & \\
\hline
\end{tabular}

\subsection{Aqueous electrolytes}

Water is certainly an appealing universal solvent for electrolytes due to its availability and sustainable nature. Several electrolytes, such as acids, inorganic salts and bases, were generally adopted in aqueous systems. In this case, the graphite electrode usually works as an anode; water serves not only as a solvent but can also introduce $\mathrm{C}-\mathrm{O}$ bonds in the graphite boundary at the initial stage. Afterwards, negative-charged guest anions intercalate and initiate the expansion and further exfoliation.

The use of acids as electrolytes can be traced back to the 1990 s [97]. The formation of a surface blister on graphite has been extensively studied using electrochemical oxidation in sulfuric acid [98]. However, the excessive oxidation of the graphite surface results in thin graphene oxide (GO) sheets with severe defects. When a relatively high positive voltage (e.g., 10V) was applied to the graphite electrode in dilute sulfuric acid, the exfoliation of graphite was realized by the violent releasing of gases via the electrochemical reduction of sulfate ions $\left(\mathrm{SO}_{4}{ }^{2-}\right)$ [99]. Compared to many other protonic acid aqueous electrolytes, such as hydrobromic acid $(\mathrm{HBr})$, hydrochloric acid $(\mathrm{HCl})$, perchloric acid $\left(\mathrm{HClO}_{4}\right)$ and nitric acid $\left(\mathrm{HNO}_{3}\right)$, the lower reduction potential $(0.172 \mathrm{~V})$ renders sulfuric acid $\left(\mathrm{H}_{2} \mathrm{SO}_{4}\right)$ an ideal electrolyte for the exfoliation of natural graphite flakes or highly oriented pyrolytic graphite (HOPG). In a typical experimental setup, a platinum wire is used as a counter electrode, graphite is used as a working electrode, and aqueous $\mathrm{H}_{2} \mathrm{SO}_{4}$ is used as an electrolyte solution (Fig. 5a). The mechanism for the electrochemical exfoliation process of graphite is as follows: (i) electrolysis of water at the electrode produces hydroxyl and oxygen radicals; (ii) the as-produced radicals initially oxidize the edge and/or grain boundaries of the graphite; (iii) oxidation at the edge and grain boundaries leads to the depolarization and the expansion of the graphite layers, thereby facilitating the intercalation of $\mathrm{SO}_{4}{ }^{2-}$ anions within the graphitic layers along with water; and (iv) reduction of the intercalated $\mathrm{SO}_{4}{ }^{2-}$ anions and self-oxidation of water produces gaseous species, such as $\mathrm{SO}_{2}$ and $\mathrm{O}_{2}$, which exert a large force on the graphite layers and thereby separate weakly bonded graphite layers from one another (Fig. 5e). This hypothesis was further supported by a report from Palermo and co-workers, in which they investigated the surface morphology of the graphite electrode with different electrochemical reaction times by AFM and optical microscopy [100]. Relevant blister formation due to the evolution of gaseous species was observed after a few seconds of treatment when sufficient voltage was applied. The blisters have a large size of up to several tens of $\mu \mathrm{m}$ and tend to cluster together. The blisters continuously grow upon explosion or gas release, and then they collapse, forming network of ripples. 

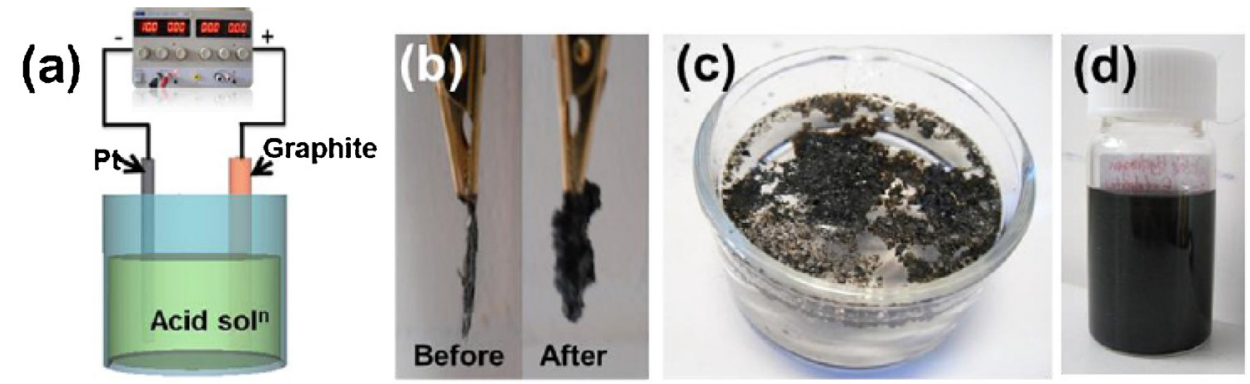

(e)

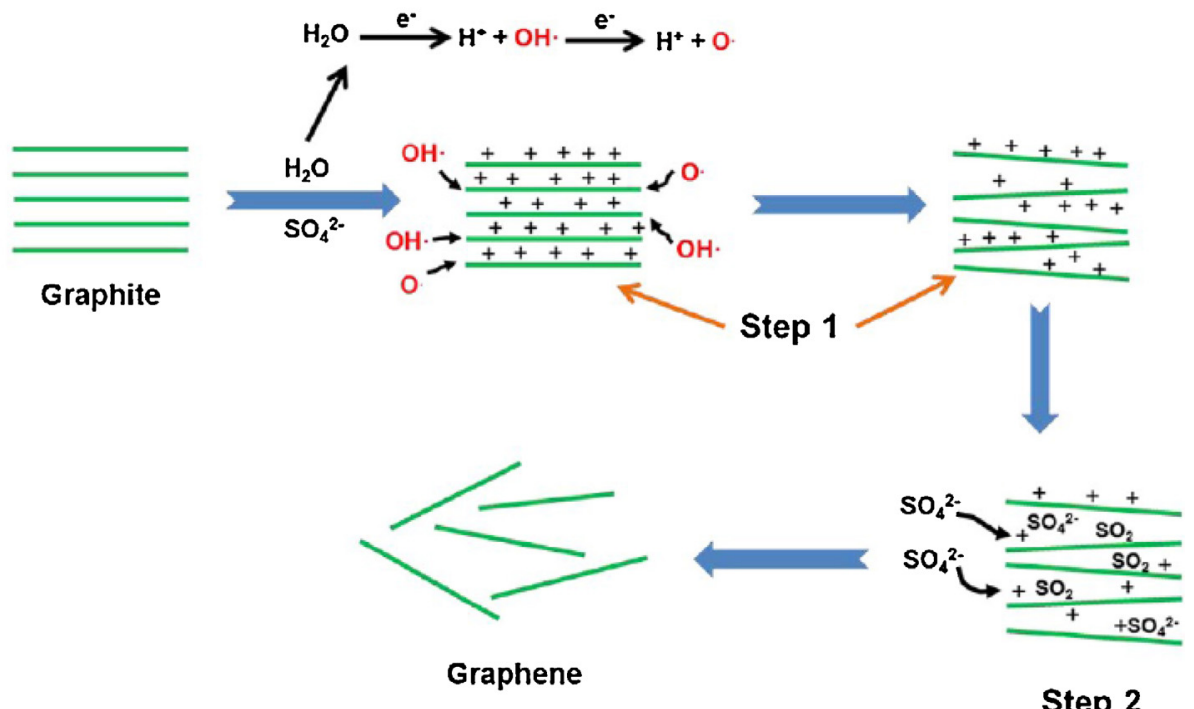

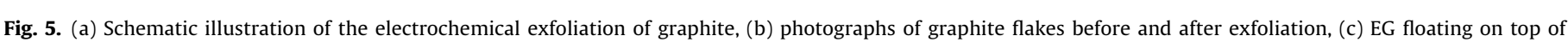

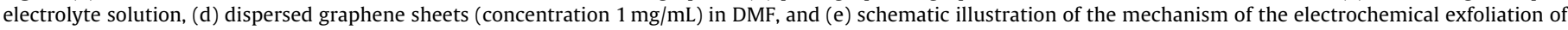
graphite to graphene.

Reproduced from Ref. [101] with permission from the American Chemical Society.

The electrochemical exfoliation of highly ordered pyrolytic graphite (HOPG) in a $\mathrm{H}_{2} \mathrm{SO}_{4}$ and $\mathrm{KOH}$ mixed electrolyte resulted in high-quality, thin graphene layers [99]. The as-prepared electrochemically exfoliated graphene (EG) exhibited a field-effect mobility of up to $17 \mathrm{~cm}^{2} / \mathrm{V} \mathrm{s}$. Unfortunately, the yield of the exfoliated graphene was only $5-8 \mathrm{wt} \%$ with a concentration of only $0.085 \mathrm{mg} / \mathrm{mL}$ in DMF, and more than $65 \%$ of the exfoliated graphene sheets were less than $2 \mathrm{~nm}$. Later, by varying the concentration of $\mathrm{H}_{2} \mathrm{SO}_{4}$ and/or bias voltage, our group [101] achieved a higher yield of EG ( $\sim 60 \mathrm{wt} \%$ ) with a concentration up to $1 \mathrm{mg} / \mathrm{mL}$ in DMF (Fig. 5d). A detailed investigation on the concentration of the electrolyte revealed that the yield of EG was significantly low when the concentration of $\mathrm{H}_{2} \mathrm{SO}_{4}$ was less than $0.1 \mathrm{M}$. The EG obtained in $0.1 \mathrm{M} \mathrm{H}_{2} \mathrm{SO}_{4}$ exhibited a high content (i.e., 80\%) of 1-3 layers of graphene with a $\mathrm{C} / \mathrm{O}$ ratio of 12.3 . Moreover, a typical bilayer EG presented a field-effect mobility of $233 \mathrm{~cm}^{2} / \mathrm{Vs}$. The patterned EG film can serve as high-performance electrodes for organic field-effect transistors. In addition to $\mathrm{H}_{2} \mathrm{SO}_{4}$, a phosphoric acid $\left(\mathrm{H}_{3} \mathrm{PO}_{4}\right)$-based electrolyte has also been reported to successfully exfoliate graphite [102]. Using a pencil core as the graphite electrode and $1 \mathrm{M} \mathrm{H}_{3} \mathrm{PO}_{4}$ as the electrolyte, graphene flakes with an average thickness of 3-6 nm were obtained.

The use of strong acids such as $\mathrm{H}_{2} \mathrm{SO}_{4}$ and $\mathrm{H}_{3} \mathrm{PO}_{4}$ severely compromises the quality of graphene because the cooperative oxidation of hydrogen ions $\left(\mathrm{H}^{+}\right)$and sulfate ions $\left(\mathrm{SO}_{4}{ }^{2-}\right)$ will lead to the over-oxidation of graphene, although the oxidation of graphene during the electrochemical processes is less extensive than that during chemical oxidation approaches. One possible approach to avoid over-oxidation and thereby improve the quality of EG is to select electrolytes with neutral $\mathrm{pH}$, such as aqueous inorganic salt electrolytes. Ammonium sulfate $\left(\left(\mathrm{NH}_{4}\right)_{2} \mathrm{SO}_{4}\right)$ is the best candidate among many sulfate salts (e.g., sodium sulfate $\left(\mathrm{Na}_{2} \mathrm{SO}_{4}\right)$, potassium sulfate $\left(\mathrm{K}_{2} \mathrm{SO}_{4}\right)$, etc.). The exfoliation of graphite in $0.1 \mathrm{M}$ $\left(\mathrm{NH}_{4}\right)_{2} \mathrm{SO}_{4}$ resulted in over $75 \%$ thin graphene layers with a concentration of $2.5 \mathrm{mg} / \mathrm{mL}$ in DMF. The obtained EG exhibited an outstanding C/O ratio of 17.2 with a lateral size of graphene of up to $44 \mu \mathrm{m}$. The Raman spectra further revealed that the EG sheets contained a low defect density $\left(I_{\mathrm{D}} / I_{\mathrm{G}}\right.$ ratio of 0.25$)$ compared to that of $\mathrm{H}_{2} \mathrm{SO}_{4}$-exfoliated EG. Consequently, the graphene exfoliated in the inorganic salt electrolytes exhibited a high mobility of $310 \mathrm{~cm}^{2} / \mathrm{V} \mathrm{s}$. Importantly, this exfoliation process can be readily scaled up, and over $16 \mathrm{~g}$ of high-quality EG has been produced in less than hour [103].

In addition to acidic and/or inorganic salt-based electrolytes, the basic electrolyte medium has also been reported to prepare graphene by electrochemical exfoliation. For example, a sodium hydroxide/hydrogen peroxide/water $\left(\mathrm{NaOH} / \mathrm{H}_{2} \mathrm{O}_{2} / \mathrm{H}_{2} \mathrm{O}\right)$ system was explored as an alternative electrolyte system toward highquality, few-layer graphene (AFLG) [104]. Nucleophilic peroxide ions generated by the reaction of $\mathrm{H}_{2} \mathrm{O}_{2}$ with hydroxyl ions $\left(\mathrm{HO}^{-}\right)$ play a role as oxidants to open up the sheet edges for the complete separation of the graphene layers. After exfoliation, the obtained product showed a high yield (95\%) of 3-6 layers of graphene, but after centrifuging, the yield decreased to $58 \%$ containing mainly 
3 layers. The as-prepared AFLG exhibited a higher defect density $\left(I_{\mathrm{D}} / I_{\mathrm{G}}\right.$ ratio 0.67$)$ compared to that of acid and/or inorganic sulfate salt exfoliated EG.

In addition to the aforementioned acid, base and/or inorganic salt-based electrolytes, the electrochemical exfoliation of graphite has also been performed in aqueous surfactant poly(sodium-4styrenesulfonate) (PSS)-based electrolytes by applying a potential of $5 \mathrm{~V}$ on the graphite rod electrodes for $4 \mathrm{~h}$ [105]. During the electrochemical process, polystyrene sulfonate anions were forced to move under the electric force to the positive graphite electrode and intercalate into graphitic layers, leading to the exfoliation of the graphene. A yield of $15 \mathrm{wt} \%$ was achieved using this method. Nevertheless, PSS was found to be decorated on the graphene surface even after repeated washings, which significantly affected the electronic properties of graphene. Moreover, SDS surfactant in aqueous solution was also employed for the graphite intercalation process by applying a positive potential of $+2 \mathrm{~V}$ to intercalate SDS molecules into the graphitic layers followed by a negative potential of $-1 \mathrm{~V}$ to drive the exfoliation process. Graphene flakes with an average size of $500 \mathrm{~nm}$ and a thickness of $1 \mathrm{~nm}$ (one or two layers) were successfully obtained [106]. However, similar to the liquid-phase exfoliation methods, the use of surfactants may cause irreversible functionalization of graphene sheets that may ultimately affect the electronic properties of graphene.

\section{Supercritical fluid exfoliation}

Graphene sheets can also be produced by intercalating graphite with supercritical fluids. This technique is potentially fast and has yielded pristine graphene sheets. The supercritical exfoliation of intercalated graphite using carbon monoxide ( $\mathrm{CO}$ ) produces graphene sheets of a few micrometers. However, the minimum thickness of graphene sheets was $3.8 \mathrm{~nm}$, corresponding to approximately 10 layers [107]. Better results were obtained in later studies using DMF, NMP and ethanol rather than CO in combination with a brief (i.e., $10 \mathrm{~min}$ ) initial low-power sonication of the materials and then heated above the critical temperature of the solvents [108]. All three solvents led to stable graphene dispersions with a concentration of $2-4 \mathrm{mg} / \mathrm{mL}$. Moreover, approximately $90-95 \%$ of the exfoliated graphene sheets were less than 8 layers, including $10 \%$ monolayer graphene. Subsequent efforts have been made to improve this exfoliation method. For example, using 1-pyrene sulfonic acid sodium salt (1-PSA) surfactants during expansion improved the percentage of monolayer graphene that was obtained from $10 \%$ to $60 \%$ [109]. The graphene sheets were found to be decorated with 1-PSA. The sulfonic acid groups in 1-PSA can play a role as electron withdrawing groups resulting in an electron transfer from the graphene to the 1-PSA molecules and thereby, significantly affect the electronic properties of graphene.

\section{Conclusions and outlook}

The large-scale preparation of graphene is of great importance because many applications rely on the bulk-scale production of exfoliated materials with controlled properties. In this review, we have demonstrated that graphene can be obtained via various wet chemical routes. As summarized in Table 3, each of these methods has advantages and limitations. The liquid-phase exfoliation of bulk graphite is mild, non-oxidative and potentially scalable. Recently, a breakthrough in this approach was made by Coleman and co-workers, using shear exfoliation method in NMP, resulting in improved exfoliation efficiency with defect free, unoxidized graphene sheets achieved in liquid volumes from hundreds of milliliters up to hundreds of liters [110]. Nevertheless, the yield of thin graphene layer remains low with limited processability and
Table 3

Summary of the advantages and disadvantages associated with graphene production by wet chemical routes.

\begin{tabular}{|c|c|c|}
\hline $\begin{array}{l}\text { Graphene exfoliation } \\
\text { methods }\end{array}$ & Advantages & Disadvantages \\
\hline $\begin{array}{l}\text { Liquid-phase } \\
\text { exfoliation }\end{array}$ & $\begin{array}{l}\text { High-quality } \\
\text { Simple preparation } \\
\text { method } \\
\text { Potentially scalable } \\
\text { Non-oxidative route }\end{array}$ & $\begin{array}{l}\text { Low yield of thin } \\
\text { graphene layers } \\
\text { Small flake size }(<5 \mu \mathrm{m}) \\
\text { Limited dispersability } \\
\text { Limited processability }\end{array}$ \\
\hline $\begin{array}{l}\text { Graphene from } \\
\text { graphite oxide }\end{array}$ & $\begin{array}{l}\text { High yield } \\
\text { High dispersability } \\
\text { High processability } \\
\text { Scalable method }\end{array}$ & $\begin{array}{l}\text { Poor quality and/or } \\
\text { defective structures } \\
\text { Potentially explosive } \\
\text { process } \\
\text { Time consuming } \\
\text { Use of toxic chemicals } \\
\text { Poor electronic } \\
\text { properties }\end{array}$ \\
\hline $\begin{array}{l}\text { Electrochemical } \\
\text { exfoliation }\end{array}$ & $\begin{array}{l}\text { High yield } \\
\text { Fast production } \\
\text { Cost effectiveness } \\
\text { High processability } \\
\text { Environmentally benign } \\
\text { Scalable } \\
\text { Good electronic } \\
\text { properties }\end{array}$ & $\begin{array}{l}\text { Slight oxidation } \\
\text { Inhomogeneous flake } \\
\text { thickness }\end{array}$ \\
\hline $\begin{array}{l}\text { Supercritical fluid } \\
\text { exfoliation }\end{array}$ & $\begin{array}{l}\text { Potentially fast method } \\
\text { Ease of processing }\end{array}$ & $\begin{array}{l}\text { Low yield of thin } \\
\text { graphene layers } \\
\text { Electronic properties are } \\
\text { affected }\end{array}$ \\
\hline
\end{tabular}

dispersibility. The typical concentration of LPE graphene is less than $1 \mathrm{mg} / \mathrm{mL}$ in organic solvents and it is unclear if the processability of such graphene can be further improved or not in the future. Furthermore, once the exfoliated graphene sheets are solidified from the solvents, they tend to strongly aggregate due to van der Waals attraction, compromising the efforts made during exfoliation. On the other hand, the graphene oxide route produces a high yield of single layer graphene with excellent solution processability, but it suffers from extremely poor quality or structural inhomogeneity. So far, the best quality of reduced GO has a defect density (i.e. $I_{\mathrm{D}} / I_{\mathrm{G}}$ ratio) of $<1$ and a field-effect mobility of only $250 \mathrm{~cm}^{2} / \mathrm{V} \mathrm{s}$ which is comparatively lower than that of LPE and/or electrochemically exfoliated graphene. Moreover, the defects within GO cannot be fully restored with current reduction methods. In addition, the preparation of graphene oxide requires the use of large amount of acids and/or oxidizing agents and the process usually takes up to several days, which hinders their industrial scale production. Clearly, electrochemical exfoliation is an excellent approach for producing high quality graphene via a wet chemical route. This method appears to provide a solution for overcoming the limitations of both the liquid-phase exfoliation and graphite oxide methods by producing high-quality graphene at a large scale within a short time period and in an environmentally friendly manner. However, the remaining challenges for this approach are producing graphene with a homogeneous flake size and layer distribution. Despite intensive research in this area, a deep understanding of the fundamental mechanism during exfoliation is critical for future studies to achieve size-controllable graphene with lower defects. The supercritical fluid exfoliation technique is also a very promising method for the preparation of graphene because ease of processing and a significant number of monolayers can be obtained using this method. Nevertheless, graphene prepared by a scalable method is crucial for their real time applications in conductive ink, composite materials, supercapacitors, fuel cells, batteries, etc. In particular, not only the application performance of graphene must outperform but also the production cost should be less than the existing carbon materials such as carbon black, carbon nanotubes, activated carbon, in order to motivate the industries to adopt this new material. 


\section{Acknowledgements}

The authors acknowledge the financial support from the ERC grant on NANOGRAPH and 2DMATER, EU Projects MoQuas and UPGRADE, EC under Graphene Flagship (No. CNECT-ICT-604391), INSOLCELL and MaxNet Energy. The authors also thank the financial support from the Center for Advancing Electronics Dresden (cfaed) and China Scholarship Council (CSC).

\section{References}

[1] A.K. Geim, K.S. Novoselov, Nat. Mater. 6 (2007) 183-191.

[2] A.K. Geim, Science 324 (2009) 1530-1534.

[3] S. Park, R.S. Ruoff, Nat. Nanotechnol. 4 (2009) 217-224.

[4] C. Schafhaeutl, J. Prakt. Chem. 19 (1840) 159-174.

[5] D.V. Badami, Nature 193 (1962) 569-570.

[6] K.S. Novoselov, A.K. Geim, S.V. Morozov, D. Jiang, Y. Zhang, S.V. Dubonos, I.V. Grigorieva, A.A. Firsov, Science 306 (2004) 666-669.

[7] K.S. Novoselov, D. Jiang, F. Schedin, T.J. Booth, V.V. Khotkevich, S.V. Morozov, A.K. Geim, Proc. Natl. Acad. Sci. U. S. A. 102 (2005) 10451-10453.

[8] K.I. Bolotin, K.J. Sikes, Z. Jiang, M. Klima, G. Fudenberg, J. Hone, P. Kim, H.L. Stormer, Solid State Commun. 146 (2008) 351-355

[9] A.A. Balandin, S. Ghosh, W. Bao, I. Calizo, D. Teweldebrhan, F. Miao, C.N. Lau, Nano Lett. 8 (2008) 902-907.

[10] C. Lee, X. Wei, J.W. Kysar, J. Hone, Science 321 (2008) 385-388.

[11] H.K. Chae, D.Y. Siberio-Perez, J. Kim, Y. Go, M. Eddaoudi, A.J. Matzger, M. O’Keeffe, O.M. Yaghi, Nature 427 (2004) 523-527.

[12] R.R. Nair, P. Blake, A.N. Grigorenko, K.S. Novoselov, T.J. Booth, T. Stauber, N.M. Peres, A.K. Geim, Science 320 (2008) 1308.

[13] X. Wang, L. Zhi, K. Müllen, Nano Lett. 8 (2008) 323-327.

[14] J. Wu, M. Agrawal, H.A. Becerril, Z. Bao, Z. Liu, Y. Chen, P. Peumans, ACS Nano 4 (2010) 43-48.

[15] S. Pang, H.N. Tsao, X. Feng, K. Müllen, Adv. Mater. 21 (2009) 3488-3491

[16] C.-A. Di, D. Wei, G. Yu, Y. Liu, Y. Guo, D. Zhu, Adv. Mater. 20 (2008) 3289-3293.

[17] R. Li, Z. Liu, K. Parvez, X. Feng, K. Müllen, J. Mater. Chem. C 3 (2015) 37-40.

[18] Z. Liu, K. Parvez, R. Li, R. Dong, X. Feng, K. Müllen, Adv. Mater. 27 (2015) 669-675.

[19] S. Bae, H. Kim, Y. Lee, X. Xu, J.S. Park, Y. Zheng, J. Balakrishnan, T. Lei, H.R. Kim, Y.I. Song, Y.J. Kim, K.S. Kim, B. Ozyilmaz, J.H. Ahn, B.H. Hong, S. Iijima, Nat. Nanotechnol. 5 (2010) 574-578.

[20] K. Parvez, S. Yang, Y. Hernandez, A. Winter, A. Turchanin, X. Feng, K. Müllen, ACS Nano 6 (2012) 9541-9550.

[21] Z.S. Wu, S. Yang, Y. Sun, K. Parvez, X. Feng, K. Müllen, J. Am. Chem. Soc. 134 (2012) 9082-9085.

[22] Z.-S. Wu, K. Parvez, X. Feng, K. Müllen, J. Mater. Chem. A 2 (2014) 8288-8293.

[23] Z.S. Wu, K. Parvez, X. Feng, K. Müllen, Nat. Commun. 4 (2013) 2487.

[24] Z.S. Wu, K. Parvez, A. Winter, H. Vieker, X. Liu, S. Han, A. Turchanin, X. Feng, K. Müllen, Adv. Mater. 26 (2014) 4552-4558.

[25] Z.S. Wu, W. Ren, L. Wen, L. Gao, J. Zhao, Z. Chen, G. Zhou, F. Li, H.M. Cheng, ACS Nano 4 (2010) 3187-3194.

[26] K.S. Kim, Y. Zhao, H. Jang, S.Y. Lee, J.M. Kim, K.S. Kim, J.H. Ahn, P. Kim, J.Y. Choi, B.H. Hong, Nature 457 (2009) 706-710.

[27] V. León, A.M. Rodriguez, P. Prieto, M. Prato, E. Vázquez, ACS Nano 8 (2013) 563-571.

[28] Y. Hernandez, V. Nicolosi, M. Lotya, F.M. Blighe, Z. Sun, S. De, I.T. McGovern, B. Holland, M. Byrne, Y.K. Gun'Ko, J.J. Boland, P. Niraj, G. Duesberg, S. Krishnamurthy, R. Goodhue, J. Hutchison, V. Scardaci, A.C. Ferrari, J.N. Coleman, Nat. Nanotechnol. 3 (2008) 563-568.

[29] M. Lotya, Y. Hernandez, P.J. King, R.J. Smith, V. Nicolosi, L.S. Karlsson, F.M. Blighe, S. De, Z. Wang, I.T. McGovern, G.S. Duesberg, J.N. Coleman, J. Am. Chem. Soc. 131 (2009) 3611-3620.

[30] U. Khan, A. O’Neill, M. Lotya, S. De, J.N. Coleman, Small 6 (2010) 864-871.

[31] S. Wang, Y. Zhang, N. Abidi, L. Cabrales, Langmuir 25 (2009) 11078-11081.

[32] C.E. Hamilton, J.R. Lomeda, Z. Sun, J.M. Tour, A.R. Barron, Nano Lett. 9 (2009) 3460-3462.

[33] A.B. Bourlinos, V. Georgakilas, R. Zboril, T.A. Steriotis, A.K. Stubos, Small 5 (2009) 1841-1845.

[34] S.P. Economopoulos, G. Rotas, Y. Miyata, H. Shinohara, N. Tagmatarchis, ACS Nano 4 (2010) 7499-7507.

[35] F. Torrisi, T. Hasan, W. Wu, Z. Sun, A. Lombardo, T.S. Kulmala, G.W. Hsieh, S. Jung, F. Bonaccorso, P.J. Paul, D. Chu, A.C. Ferrari, ACS Nano 6 (2012) 2992-3006.

[36] M. Quintana, M. Grzelczak, K. Spyrou, B. Kooi, S. Bals, G. Van Tendeloo, P. Rudolf, M. Prato, Chem. Commun. 48 (2012) 12159-12161.

[37] J.M. Englert, C. Dotzer, G. Yang, M. Schmid, C. Papp, J.M. Gottfried, H.P. Steinruck, E. Spiecker, F. Hauke, A. Hirsch, Nat. Chem. 3 (2011) 279-286.

[38] A. Ciesielski, S. Haar, M. El Gemayel, H. Yang, J. Clough, G. Melinte, M. Gobbi, E. Orgiu, M.V. Nardi, G. Ligorio, V. Palermo, N. Koch, O. Ersen, C. Casiraghi, P. Samorì, Angew. Chem. Int. Ed. 53 (2014) 10355-10361.

[39] S. Haar, A. Ciesielski, J. Clough, H. Yang, R. Mazzaro, F. Richard, S. Conti, N. Merstorf, M. Cecchini, V. Morandi, C. Casiraghi, P. Samorì, Small 11 (2015) 1691-1702.
[40] W. Qian, R. Hao, Y.L. Hou, Y. Tian, C.M. Shen, H.J. Gao, X.L. Liang, Nano Res. 2 (2009) 706-712.

[41] X.Y.Zhang, A.C. Coleman, N. Katsonis, W.R. Browne, B.J. van Wees, B.L. Feringa Chem. Commun. 46 (2010) 7539-7541.

[42] R. Kabe, X. Feng, C. Adachi, K. Müllen, Chem. - Asian J. 9 (2014) 3125-3129.

[43] A. Ciesielski, P. Samori, Chem. Soc. Rev. 43 (2014) 381-398.

[44] O.M. Marago, F. Bonaccorso, R. Saija, G. Privitera, P.G. Gucciardi, M.A. Iati, G. Calogero, P.H. Jones, F. Borghese, P. Denti, V. Nicolosi, A.C. Ferrari, ACS Nano 4 (2010) 7515-7523.

[45] A.A. Green, M.C. Hersam, Nano Lett. 9 (2009) 4031-4036.

[46] S. De, P.J. King, M. Lotya, A. O’Neill, E.M. Doherty, Y. Hernandez, G.S. Duesberg, J.N. Coleman, Small 6 (2010) 458-464.

[47] L. Guardia, M.J. Fernández-Merino, J.I. Paredes, P. Solís-Fernández, S. VillarRodil, A. Martínez-Alonso, J.M.D. Tascón, Carbon 49 (2011) 1653-1662.

[48] H. Yang, Y. Hernandez, A. Schlierf, A. Felten, A. Eckmann, S. Johal, P. Louette J.J. Pireaux, X. Feng, K. Müllen, V. Palermo, C. Casiraghi, Carbon 53 (2013) 357-365.

[49] X.Q. Wang, P.F. Fulvio, G.A. Baker, G.M. Veith, R.R. Unocic, S.M. Mahurin, M.F Chi, S. Dai, Chem. Commun. 46 (2010) 4487-4489.

[50] D. Nuvoli, L. Valentini, V. Alzari, S. Scognamillo, S.B. Bon, M. Piccinini, J. Illescas A. Mariani, J. Mater. Chem. 21 (2011) 3428-3431.

[51] X.L. Li, G.Y. Zhang, X.D. Bai, X.M. Sun, X.R. Wang, E. Wang, H.J. Dai, Nat. Nanotechnol. 3 (2008) 538-542.

[52] S.Y. Choi, M. Mamak, E. Cordola, U. Stadler, J. Mater. Chem. 21 (2011) 5142-5147.

[53] S.R. Dhakate, N. Chauhan, S. Sharma, J. Tawale, S. Singh, P.D. Sahare, R.B. Mathur, Carbon 49 (2011) 1946-1954.

[54] V.C. Tung, M.J. Allen, Y. Yang, R.B. Kaner, Nat. Nanotechnol. 4 (2009) 25-29.

[55] D. Li, M.B. Muller, S. Gilje, R.B. Kaner, G.G. Wallace, Nat. Nanotechnol. 3 (2008) $101-105$.

[56] N. Behabtu, J.R. Lomeda, M.J. Green, A.L. Higginbotham, A. Sinitskii, D.V. Kosynkin, D. Tsentalovich, A.N. Parra-Vasquez, J. Schmidt, E. Kesselman, Y. Cohen, Y. Talmon, J.M. Tour, M. Pasquali, Nat. Nanotechnol. 5 (2010) 406-411.

[57] W.S. Hummers, R.E. Offeman, J. Am. Chem. Soc. 80 (1958) 1339.

[58] D.C. Marcano, D.V. Kosynkin, J.M. Berlin, A. Sinitskii, Z. Sun, A. Slesarev, L.B. Alemany, W. Lu, J.M. Tour, ACS Nano 4 (2010) 4806-4814.

[59] A.M. Dimiev, J.M. Tour, ACS Nano 8 (2014) 3060-3068.

[60] D.R. Dreyer, S. Park, C.W. Bielawski, R.S. Ruoff, Chem. Soc. Rev. 39 (2010) 228-240.

[61] K.R. Koch, J. Chem. Ed. 59 (1982) 973

[62] S. Eigler, M. Enzelberger-Heim, S. Grimm, P. Hofmann, W. Kroener, A. Geworski, C. Dotzer, M. Rockert, J. Xiao, C. Papp, O. Lytken, H.P. Steinruck, P. Müller, A. Hirsch, Adv. Mater. 25 (2013) 3583-3587.

[63] C. Mattevi, G. Eda, S. Agnoli, S. Miller, K.A. Mkhoyan, O. Celik, D. Mastrogiovanni, G. Granozzi, E. Garfunkel, M. Chhowalla, Adv. Funct. Mater. 19 (2009) 2577-2583.

[64] V. López, R.S. Sundaram, C. Gómez-Navarro, D. Olea, M. Burghard, J. GómezHerrero, F. Zamora, K. Kern, Adv. Mater. 21 (2009) 4683-4686.

[65] C.-Y. Su, Y. Xu, W. Zhang, J. Zhao, X. Tang, C.-H. Tsai, L.-J. Li, Chem. Mater. 21 (2009) 5674-5680.

[66] C.-Y. Su, Y. Xu, W. Zhang, J. Zhao, A. Liu, X. Tang, C.-H. Tsai, Y. Huang, L.-J. Li, ACS Nano 4 (2010) 5285-5292.

[67] G. Eda, G. Fanchini, M. Chhowalla, Nat. Nanotechnol. 3 (2008) 270-274

[68] S. Stankovich, D.A. Dikin, R.D. Piner, K.A. Kohlhaas, A. Kleinhammes, Y. Jia, Y. Wu, S.T. Nguyen, R.S. Ruoff, Carbon 45 (2007) 1558-1565.

[69] V.H. Pham, T.V. Cuong, T.-D. Nguyen-Phan, H.D. Pham, E.J. Kim, S.H. Hur, E.W. Shin, S. Kim, J.S. Chung, Chem. Commun. 46 (2010) 4375-4377.

[70] V.H. Pham, S.H. Hur, E.J. Kim, B.S. Kim, J.S. Chung, Chem. Commun. 49 (2013) 6665-6667.

[71] S.F. Pei, J.P. Zhao, J.H. Du, W.C. Ren, H.M. Cheng Carbon 48 (2010) 4466-4474

[72] I.K. Moon, J. Lee, R.S. Ruoff, H. Lee, Nat. Commun. 1 (2010) 73.

[73] J. Che, L. Shen, Y. Xiao, J. Mater. Chem. 20 (2010) 1722-1727.

[74] H. Feng, R. Cheng, X. Zhao, X. Duan, J. Li, Nat. Commun. 4 (2013) 1539.

[75] V.H. Pham, H.D. Pham, T.T. Dang, S.H. Hur, E.J. Kim, B.S. Kong, S. Kim, J.S. Chung J. Mater. Chem. 22 (2012) 10530-10536.

[76] X. Mei, J. Ouyang, Carbon 49 (2011) 5389-5397.

[77] C.K. Chua, A. Ambrosi, M. Pumera, J. Mater. Chem. 22 (2012) 11054-11061.

[78] C. Vallés, J. David Núñez, A.M. Benito, W.K. Maser, Carbon 50 (2012) 835-844.

[79] S. Wang, P.K. Ang, Z. Wang, A.L. Tang, J.T. Thong, K.P. Loh, Nano Lett. 10 (2010) 92-98.

[80] Y.Y. Liang, J. Frisch, L.J. Zhi, H. Norouzi-Arasi, X.L. Feng, J.P. Rabe, N. Koch, K. Mullen, Nanotechnology 20 (2009) 434007.

[81] S.W. Lee, C. Mattevi, M. Chhowalla, R.M. Sankaran, J. Phys. Chem. Lett. 3 (2012) $772-777$.

[82] H. Li, S. Pang, S. Wu, X. Feng, K. Müllen, C. Bubeck, J. Am. Chem. Soc. 133 (2011) 9423-9429.

[83] H.N. Tien, V.H. Luan, T.K. Lee, B.-S. Kong, J.S. Chung, E.J. Kim, S.H. Hur, Chem. Eng. J. 211-212 (2012) 97-103.

[84] S. Dubin, S. Gilje, K. Wang, V.C. Tung, K. Cha, A.S. Hall, J. Farrar, R. Varshneya, Y. Yang, R.B. Kaner, ACS Nano 4 (2010) 3845-3852.

[85] S. Pei, H.-M. Cheng, Carbon 50 (2012) 3210-3228.

[86] H.J. Shin, K.K. Kim, A. Benayad, S.M. Yoon, H.K. Park, I.S. Jung, M.H. Jin, H.K. Jeong, J.M. Kim, J.Y. Choi, Y.H. Lee, Adv. Funct. Mater. 19 (2009) 1987-1992.

[87] S. Stankovich, D.A. Dikin, G.H.B. Dommett, K.M. Kohlhaas, E.J. Zimney, E.A. Stach, R.D. Piner, S.T. Nguyen, R.S. Ruoff, Nature 442 (2006) 282-286. 
[88] J.O. Besenhard, Carbon 14 (1976) 111-115.

[89] C.T.J. Low, F.C. Walsh, M.H. Chakrabarti, M.A. Hashim, M.A. Hussain, Carbon 54 (2013) 1-21.

[90] N. Liu, F. Luo, H. Wu, Y. Liu, C. Zhang, J. Chen, Adv. Funct. Mater. 18 (2008) 1518-1525.

[91] J. Lu, J.-X. Yang, J. Wang, A. Lim, S. Wang, K.P. Loh, ACS Nano 3 (2009) 2367-2375.

[92] J. Wang, K.K. Manga, Q. Bao, K.P. Loh, J. Am. Chem. Soc. 133 (2011) 8888-8891.

[93] Y.L. Zhong, T.M. Swager, J. Am. Chem. Soc. 134 (2012) 17896-17899.

[94] A.M. Abdelkader, I.A. Kinloch, R.A. Dryfe, ACS Appl. Mater. Interfaces 6 (2014) $1632-1639$.

[95] A.J. Cooper, N.R. Wilson, I.A. Kinloch, R.A.W. Dryfe, Carbon 66 (2014) 340-350.

[96] Z.Y. Xia, G. Giambastiani, C. Christodoulou, M.V. Nardi, N. Koch, E. Treossi, V. Bellani, S. Pezzini, F. Corticelli, V. Morandi, A. Zanelli, V. Palermo, ChemPlusChem 79 (2014) 439-446.

[97] J.M. Skowronski, Synth. Met. 55 (1993) 1447-1452.

[98] D. Alliata, P. Häring, O. Haas, R. Kötz, H. Siegenthaler, Electrochem. Commun. 1 (1999) 5-9.

[99] C.-Y. Su, A.-Y. Lu, Y. Xu, F.-R. Chen, A.N. Khlobystov, L.-J. Li, ACS Nano 5 (2011) 2332-2339.

[100] Z.Y. Xia, S. Pezzini, E. Treossi, G. Giambastiani, F. Corticelli, V. Morandi, A. Zanelli, V. Bellani, V. Palermo, Adv. Funct. Mater. 23 (2013) 4684-4693.
[101] K. Parvez, R. Li, S.R. Puniredd, Y. Hernandez, F. Hinkel, S. Wang, X. Feng, K. Müllen, ACS Nano 7 (2013) 3598-3606.

[102] J. Liu, H. Yang, S.G. Zhen, C.K. Poh, A. Chaurasia, J. Luo, X. Wu, E.K.L. Yeow, N.G. Sahoo, J. Lin, Z. Shen, RSC Adv, 3 (2013) 11745-11750.

[103] K. Parvez, Z.S. Wu, R. Li, X. Liu, R. Graf, X. Feng, K. Müllen, J. Am. Chem. Soc. 136 (2014) 6083-6091.

[104] K.S. Rao, J. Senthilnathan, Y.F. Liu, M. Yoshimura, Sci. Rep. 4 (2014) 4237

[105] G. Wang, B. Wang, J. Park, Y. Wang, B. Sun, J. Yao, Carbon 47 (2009)9 3242-3246.

[106] M. Alanyalığlu, J.J. Segura, J. Oró-Solè, N. Casañ-Pastor, Carbon 50 (2012) $142-152$

[107] N.-W. Pu, C.-A. Wang, Y. Sung, Y.-M. Liu, M.-D. Ger, Mater. Lett. 63 (2009) 1987-1989.

[108] D. Rangappa, K. Sone, M. Wang, U.K. Gautam, D. Golberg, H. Itoh, M. Ichihara, I. Honma, Chem. Eur. J. 16 (2010) 6488-6494.

[109] J.-H. Jang, D. Rangappa, Y.-U. Kwon, I. Honma, J. Mater. Chem. 21 (2011) 3462-3466.

[110] K.R. Paton, E. Varrla, C. Backes, R.J. Smith, U. Khan, A. O'Neill, C. Boland, M. Lotya, O.M. Istrate, P. King, T. Higgins, S. Barwich, P. May, P. Puczkarski, I. Ahmed, M. Moebius, H. Pettersson, E. Long, J. Coelho, S.E. O'Brien, E.K. McGuire, B.M. Sanchez, G.S. Duesberg, N. McEvoy, T.J. Pennycook, C. Downing, A. Crossley, V. Nicolosi, J.N. Coleman, Nat. Mater. 13 (2014) 624-630. 